In Cres. Vol. $4 N^{\circ}$ 2: pp. 377-379, 2013

\title{
JAIME GUZMÁN ARANDA, O LA VEHEMENTE CARRERA DE UN EDITOR PERUANO*
}

\author{
JAIME GUZMÁN ARANDA, OR THE VEHEMENT CAREER \\ OF A PERUVIAN PUBLISHER
}

Ricardo Ayllón ${ }^{1}$

Diez años antes de que el Ministerio de Educación lo pusiera en funcionamiento, Jaime Guzmán Aranda había inventado el Plan Lector en los colegios de Chimbote. El poeta, el cronista, el sociólogo, el periodista, pero sobre todo el editor, creó durante la primera mitad de la década de los 90, Río Santa Editores, el sello con el que decidió meterse en el corazón de su pueblo publicando los libros locales más representativos, e inventando para ello una frase tierna y ocurrente, un slogan categórico e inolvidable: "Un estudiante sin un libro, es como un cebiche sin ají”.

Así comenzó a recorrer aquel puerto 'violento y peliculero' (como lo bautizara Arguedas) colegio por colegio, consiguiendo instituir rápidamente -de forma rotunda y cotidiana- la literatura regional, aquella manifestación cultural que en todos los pueblos del interior se busca siempre como un trofeo, como un verificable signo de identidad y tradición.

\section{LA POESÍA COMO REQUISITO}

Aunque para estos logros hay que estar loco, hay que nacer poeta, como repetía el mismo Jaime Guzmán textualmente; y él lo fue sin ninguna duda casi

* Recibido: 15 de junio del 2013; aprobado: 06 de diciembre del 2013.

1 Abogado, egresado de la Universidad Nacional Mayor de San Marcos. Poeta, narrador y editor. Director de Ornitorrinco Editores. 
desde que aprendió a escribir. Nació en Chimbote en 1951, y durante su formación como sociólogo en la Universidad Inca Garcilaso de la Vega se hizo del Primer Premio en sus Juegos Florales de Poesía. Fue la misma época en que logró ser columnista del histórico diario La Prensa de Lima, recomendado nada menos que por Luis Alberto Sánchez, y los mismos años en que decidió integrar una de las cofradías decanas de la literatura peruana: el Grupo de Literatura Isla Blanca, fundado por Óscar Colchado Lucio en Chimbote en 1977.

Pero tendrían que llegar los años 80 para que Guzmán Aranda publicara Patio de prisión, su primer volumen de poemas, robándose para el título aquellos versos de Bob Dylan que rezan sabiamente: “A veces pienso que este mundo / no es más que un gran patio de prisión / algunos somos presos / los otros somos guardianes". Desde entonces no se detuvo, y aparecieron ininterrumpidamente sus otros poemarios, haciendo un alto únicamente para poner alma, corazón y vida en su otra gran aventura personal que fue Río Santa Editores.

\section{INGENIO Y PERSEVERANCIA}

Como editor, puso en circulación nuevamente importantes libros de narrativa casi olvidados (o ignorados por un Chimbote renuente a la lectura), entre los que destacan: Las islas blancas de Julio Ortega, Banchero, los adolescentes y alucinantes años 60 de Chimbote de Guillermo Thorndike, y Del mar a la ciudad de Óscar Colchado. Junto a ello, se arriesgó a lanzar al mercado regional otros títulos por decenas de millares, cabalgando dichoso sobre aquel otro axioma que repetía a diario y que le funcionó tan bien: "Para dejar de ser forasteros en nuestra propia tierra, leamos lo nuestro".

En su ingeniosa tarea, fundó Altamar, quizá en su momento la revista cultural más importante del departamento de Ancash, inventó 'polladas culturales', organizó ferias populares, 'descubrió' nuevos y valiosos narradores locales (como Luis Fernando Cueto, Premio Copé de Oro de Novela, o Braulio Muñoz, ganador del Premio Latino Book Award de Nueva York), llevó a Chimbote espectáculos de teatro, realizó 'marchas culturales' haciendo desfilar por las bullangueras calles chimbotanas a conocidos escribas nacionales; llegó al penal de Cambio Puente para promover la lectura entre los internos, y organizó presentaciones de libros en burdeles, únicamente en su frenético afán de llevar literatura a todo el mundo.

Dicen que padeció de sonambulismo por andar pensando solo en sus 
libros, dicen que estaba loco, dicen que era un 'chimbotano hasta las lágrimas', y dicen ahora que ha muerto, que nos dejó para siempre el 27 de mayo de este año. Pero quienes lo conocimos, sabemos que Jaime Guzmán sigue vivo y recorre aún colegios y avenidas proclamando la aparición de un nuevo libro. En algún momento llegó a ser el empresario editorial más importante del interior del Perú, y sin duda ha dejado la valla bastante alta para quien desee continuar su legado. La meta está allí, esperando por todos nosotros.

\section{SUS LIBROS}

Poemarios: Patio de prisión (1981), En la plaza (1984), Las muchedumbres (1987), Los palaciegos (1987), Lugar de nacimiento (1992), En la otra orilla (1999). Antologías: Los juglares de Chimbote (cuento y poesía), Sobre las olas. Selección de narrativa chimbotana, iSíganme los buenos! (cuentos infantiles), Chimbote, entre el fuego y el amor (crónicas), Los hervores de Chimbote en El zorro de arriba y el zorro de abajo (ensayos), La santa cede. Selección de narrativa erótica de Chimbote.

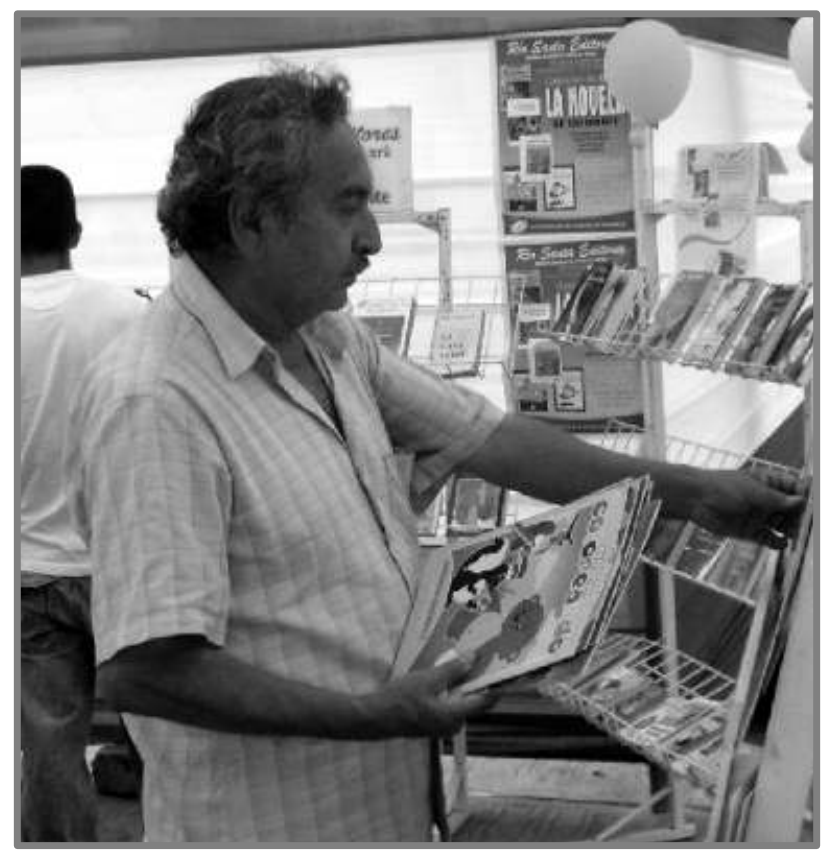

Jaime Guzmán Aranda 